\title{
Fluoropolymer Nanoparticles Prepared Using Trifluoropropene Telomer Based Fluorosurfactants
}

\author{
Wei Ma, ${ }^{a}$ Gérald Lopez, ${ }^{b}$ Bruno Ameduri, ${ }^{*}{ }^{b}$ and Atsushi Takahara ${ }^{*} a, c$
}

${ }^{a}$ International Institute for Carbon-Neutral Energy Research (WPI-I²CNER), Kyushu University,

744 Motooka, Nishi-ku, Fukuoka 819-0395, Japan

${ }^{b}$ Ingénierie et Architectures Macromoléculaires Team, Institut Charles Gerhardt, UMR 5253

CNRS, UM, ENSCM, Place Eugène Bataillon, Montpellier, France

${ }^{c}$ Institute for Materials Chemistry and Engineering, Kyushu University, 744 Motooka, Nishi-ku, Fukuoka 819-0395, Japan

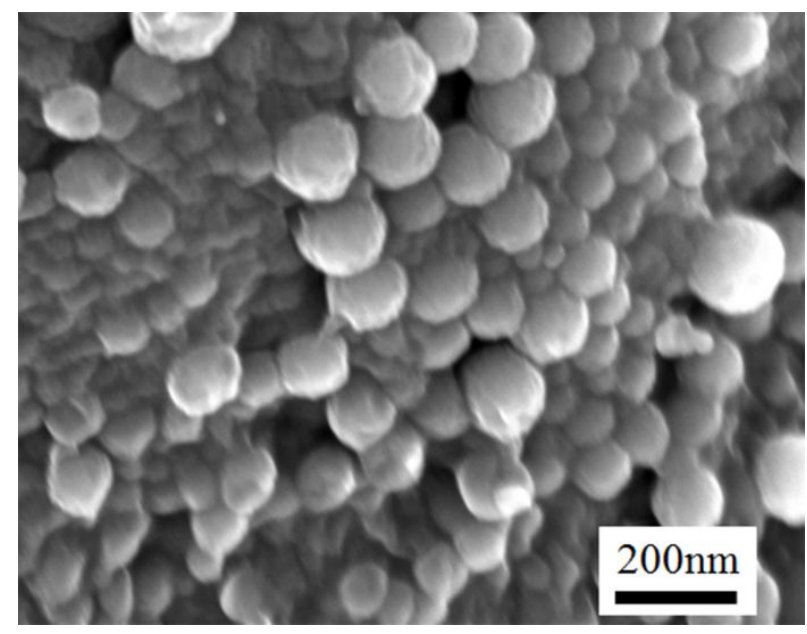

Figure S1. SEM image of the $\mathrm{PFMAC}_{4}$ nanoparticles prepared using $1.5 \mathrm{~g} / \mathrm{L}$ surfactant and 2 wt.\% poly[2-(perfluorobutyl)ethyl methacrylate] fluoropolymer after dialysis in water for $24 \mathrm{~h}$. 